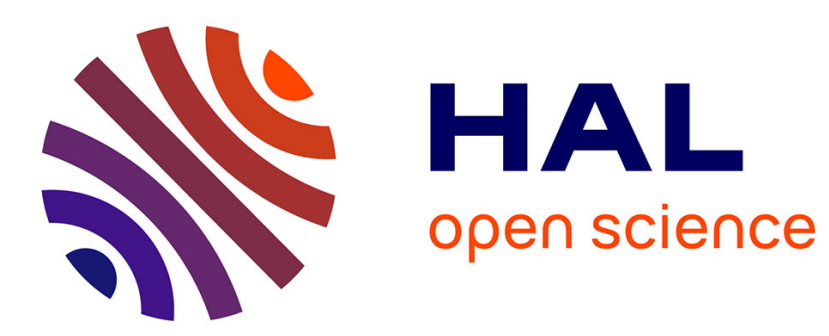

\title{
Influence of the annealing temperature on the photoluminescence of Er-doped SiO thin films
}

\author{
G. Wora Adeola, H. Rinnert, P. Miska, M. Vergnat
}

\section{To cite this version:}

G. Wora Adeola, H. Rinnert, P. Miska, M. Vergnat. Influence of the annealing temperature on the photoluminescence of Er-doped SiO thin films. Journal of Applied Physics, 2007, 102 (5), pp.053515. $10.1063 / 1.2777203$. hal-02164238

\section{HAL Id: hal-02164238 \\ https://hal.science/hal-02164238}

Submitted on 24 Jun 2019

HAL is a multi-disciplinary open access archive for the deposit and dissemination of scientific research documents, whether they are published or not. The documents may come from teaching and research institutions in France or abroad, or from public or private research centers.
L'archive ouverte pluridisciplinaire HAL, est destinée au dépôt et à la diffusion de documents scientifiques de niveau recherche, publiés ou non, émanant des établissements d'enseignement et de recherche français ou étrangers, des laboratoires publics ou privés. 


\title{
Influence of the annealing temperature on the photoluminescence of Er-doped SiO thin films
}

\author{
G. Wora Adeola, H. Rinnert, ${ }^{\text {a) }}$ P. Miska, and M. Vergnat \\ Laboratoire de Physique des Matériaux, UMR CNRS 7556, Nancy University, BP 239, \\ 54506 Vandouvre-lès-Nancy Cedex, France
}

(Received 16 February 2007; accepted 20 July 2007; published online 12 September 2007)

\begin{abstract}
Er-doped amorphous silicon suboxide thin films were prepared by the coevaporation method. The Er concentration was varied from 0.4 to 6 at. \% and the samples were annealed at different temperatures up to $900{ }^{\circ} \mathrm{C}$. The samples exhibit a broad photoluminescence band in the visible range. Both energy and intensity of this band were dependent on the annealing temperature. For as-deposited films and samples annealed below $500{ }^{\circ} \mathrm{C}$, this band was assigned to defects in the oxide films. For higher annealing temperatures, this photoluminescence band shifted to higher wavelengths and was correlated to the appearance of amorphous silicon clusters. Two narrow bands in the near-infrared range at 0.98 and $1.54 \mu \mathrm{m}$ were also observed for the annealed samples. The intensity of these Er-related luminescence was maximal for an annealing temperature equal to around $700{ }^{\circ} \mathrm{C}$. The effective absorption cross section of Er was dependent on the annealing temperature and was equal to $6.6 \times 10^{-16} \mathrm{~cm}^{2}$ for the sample annealed at $700{ }^{\circ} \mathrm{C}$. The strong Er-related photoluminescence is discussed in terms of a coupling phenomenon between $\mathrm{Er}^{3+}$ ions and spatially confined amorphous silicon clusters which act as sensitizers. The existence of a low annealing temperature to obtain the best Er-related photoluminescence is also discussed. (C) 2007 American Institute of Physics. [DOI: 10.1063/1.2777203]
\end{abstract}

\section{INTRODUCTION}

Er-doped silicon-based materials have attracted much attention in the scientific community because of their potential use for optoelectronics. ${ }^{1}$ Indeed, $\mathrm{Er}^{3+}$ ions can emit sharp luminescence at $1.54 \mu \mathrm{m}$, due to the ${ }^{4} I_{13 / 2} \rightarrow{ }^{4} I_{15 / 2}$ intra- $4 f$ transition, which corresponds to the minimum attenuation in the silica-based optical fibers commonly used in optical communications. Studies of Er-doped crystalline silicon (c-Si:Er) have shown that $\mathrm{Er}^{3+}$ ions can be efficiently excited through electron-hole pairs recombination or by impact of energetic carriers. ${ }^{2,3}$ The Er excitation is then characterized by an effective cross section of $3 \times 10^{-15} \mathrm{~cm}^{2}$ which is five orders of magnitude higher than direct-resonant optical absorption. ${ }^{2}$ However, such systems present a strong temperature quenching which is due to Auger dissociation of electron-hole pairs and energy back transfer to silicon. This thermal quenching is strongly reduced when oxygen is coimplanted and the $\mathrm{Er}$ luminescence yield at room temperature is improved. ${ }^{4,5}$ For instance, a weaker thermal quenching was observed in oxygen-doped polycrystalline or amorphous silicon which contains around $30 \%$ of oxygen. ${ }^{6}$

In the presence of silicon nanocrystals $(\mathrm{Si}-\mathrm{nc})$, the Errelated photoluminescence (PL) is strongly improved. This effect is attributed to a strong coupling between $\mathrm{Er}^{3+}$ ions and Si-nc. ${ }^{7-9} \mathrm{The} \mathrm{Er}^{3+}$ ions can then be indirectly excited by Si-nc that have an absorption cross section several orders of magnitude higher than that of direct Er excitation. Moreover, the Er nonradiative back-transfer deexcitation process is strongly reduced in presence of Si-nc, due to the widening of the band gap which produces a reduction in the free carrier

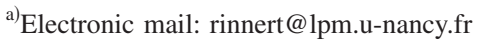

concentration. Few models describing an energy transfer from the exciton in the $\mathrm{Si}-\mathrm{nc}$ to the $\mathrm{Er}^{3+}$ ions were proposed. $^{10,11}$ In these models, photogenerated excitons in $\mathrm{Si}$-nc can either transfer their energy to $\mathrm{Er}^{3+}$ ions or give rise to a luminescence in the visible range. Several Er-doped Sibased materials were prepared by evaporation, ${ }^{12}$ chemical vapor deposition, ${ }^{13}$ sputtering, ${ }^{14}$ or implantation. ${ }^{15}$ To obtain a strong Er-related PL, a thermal annealing treatment at a temperature above $1000{ }^{\circ} \mathrm{C}$ is generally needed in order to create Si-nc.

However, recent results have shown that the existence of Si-nc is not necessary to obtain high Er-related PL efficiency. Indeed, it has been proposed that amorphous silicon clusters in $\mathrm{SiO}_{x}$ films can also act as efficient sensitizers for $\mathrm{Er}^{3+}$ ions. ${ }^{16,17}$ Additionally, Er luminescence was observed in Erdoped hydrogenated amorphous silicon. ${ }^{18,19}$ In Er-doped amorphous silicon (a-Si:Er), the PL efficiency is low at room temperature because of the existence of silicon dangling bonds, ${ }^{20}$ that can be reduced by introducing hydrogen in the structure. Moreover, as in crystalline silicon, it has been reported that oxygen improves the Er luminescence. ${ }^{21,22}$ In these amorphous systems, the excitation of $\mathrm{Er}^{3+}$ ions is not clearly understood.

This work reports on the influence of the annealing temperature on the PL properties of Er-doped $\mathrm{SiO}$ (SiO:Er) films prepared by evaporation, up to $900{ }^{\circ} \mathrm{C}$. Depending on the annealing temperature, different PL contributions are observed. For the as-deposited samples a broad PL band at around $550 \mathrm{~nm}$ is attributed to defects of the silicon oxide matrix and a very weak Er-related band at $1.54 \mu \mathrm{m}$ is observed. With annealing treatments, the intensity of the defect band in the visible range decreases and a band with a weaker 
intensity at higher wavelength appears, while the Er-related peak intensity increases with a maximum for an annealing temperature equal to $700{ }^{\circ} \mathrm{C}$. A description of the Er-related light emission yield as a function of the annealing treatments is proposed and it is suggested that the formation of a-Si clusters plays an important role in the $\mathrm{Er}^{3+}$ ions emission.

\section{EXPERIMENTAL DETAILS}

\section{A. Samples preparation}

$\mathrm{SiO}_{x}$ films with $x$ close to 1 were prepared by evaporation of $\mathrm{SiO}$ powder. The deposition rate was controlled by a quartz microbalance system and was equal to $1 \AA / \mathrm{s}$. Er evaporation was performed from an effusion cell, allowing us to obtain low deposition rates. The temperature cell was around $1100{ }^{\circ} \mathrm{C}$ and the cell was calibrated by a quartz microbalance, allowing us to control the rare-earth content. The samples were prepared with an Er concentration in the range of $0.4-6$ at. \%. The Er concentration is defined by the ratio $[\mathrm{Er}] /[\mathrm{SiO}]$. The silicon substrates were maintained at $100{ }^{\circ} \mathrm{C}$. For all samples, the total film thickness is equal to $200 \mathrm{~nm}$. The samples were then annealed in a quartz tube with a pressure of about $10^{-9}$ Torr.

\section{B. Photoluminescence characterization}

Both cw and time-resolved (TR) PL experiments were performed at room temperature. For the $\mathrm{cw}$ experiments in the visible range, the excitation was obtained with a $200 \mathrm{~W}$ mercury arc lamp source, using the UV lines at 313 and $334 \mathrm{~nm}$. The PL signal was analyzed by a monochromator equipped with a 150 grooves/mm grating and by a chargecoupled device camera detector cooled at $140 \mathrm{~K}$. For the $\mathrm{cw}$ experiments in the near-infrared domain, the sample was excited by a $30 \mathrm{~mW} \mathrm{He}-\mathrm{Cd}$ laser using the $325 \mathrm{~nm}$ line. The PL signal was analyzed by a monochromator equipped with a 600 grooves $/ \mathrm{mm}$ grating and by a photomultiplier tube cooled at $190 \mathrm{~K}$. The power dependence of the PL was studied by using neutral density filters allowing us to change the pumping power on three orders of magnitude. For the TR-PL experiments, the sample was pumped by the $355 \mathrm{~nm}$ line of a frequency-tripled yttrium aluminium garnet (YAG):Nd laser. The laser pulse frequency, energy, and duration were typically equal to $10 \mathrm{~Hz}, 50 \mu \mathrm{J}$, and $20 \mathrm{~ns}$, respectively. The detection system is the same as that used for the cw-PL experiments in the near-infrared domain. The rise time of the detector is equal to around $10 \mathrm{~ns}$. The response of the detection systems was precisely calibrated with a tungsten wire calibration source.

\section{RESULTS}

\section{A. Steady state photoluminescence}

Figure 1 shows the room-temperature cw-PL spectra in the range of 500-900 $\mathrm{nm}$ for the as-deposited $\mathrm{SiO}$ layer and for the layers annealed at different temperatures from 400 to $900{ }^{\circ} \mathrm{C}$. The as-deposited sample presents a broad PL band at $550 \mathrm{~nm}$. The sample annealed at $400{ }^{\circ} \mathrm{C}$ shows a PL band at the same wavelength, but with an eight times higher intensity. For higher annealing temperature, the PL band in-

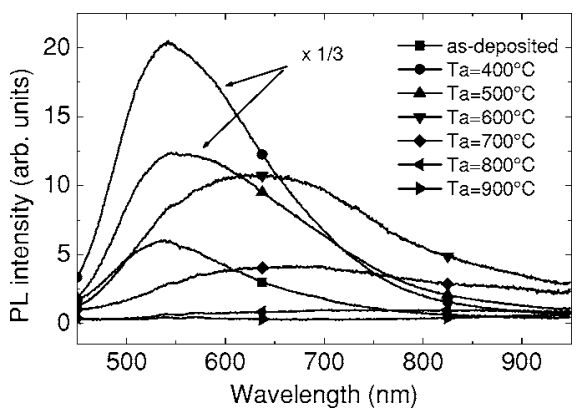

FIG. 1. Room temperature PL spectra in the range of 500-900 nm for Er-doped SiO layers annealed at different temperatures Ta. The Er concentration is equal to 0.8 at. $\%$.

tensity decreases and the wavelength redshifts. This PL evolution is very similar to that obtained in undoped $\mathrm{SiO}$ layers. $^{23}$ This evolution can be interpreted by the existence of two PL bands. The first one at around $550 \mathrm{~nm}$ is generally attributed to the presence of defects in the $\mathrm{SiO}_{x}$ matrix, such as nonbridging oxygen hole centers. ${ }^{24,25}$ Its intensity increases up to $500{ }^{\circ} \mathrm{C}$ and the energy of the maximum is almost temperature independent. For annealing temperatures higher than $500{ }^{\circ} \mathrm{C}$, this first band disappears with the suppression of the defects and a new band appears, which can be related to the phase separation process that gives rise to pure Si domains in $\mathrm{S} \mathrm{SiO}_{x}$ matrix with $x$ near 2, as shown in Ref. 26 , following the relation $2 \mathrm{SiO} \rightarrow \mathrm{Si}+\mathrm{SiO}_{2}$. The $\mathrm{PL}$ band at around $700 \mathrm{~nm}$ is then correlated to the appearance of pure silicon embedded in $\mathrm{SiO}_{x}$ matrix. The origin of this band is not clear, and several different origins could be proposed. It must be noted that no crystalline phase was observed in these samples, except for annealing temperature greater or equal to $950{ }^{\circ} \mathrm{C} .{ }^{27}$ As the size of the a-Si domains cannot be determined, no size effect can be demonstrated in these samples and it is not possible to say whether a quantum confinement effect occurs in these films. Moreover, the decay time of this band was measured and was below the detection limit of our setup, i.e., below 20 ns. This low value is not compatible with the characteristic decay time of silicon nanocrystals, which is equal to around $10 \mu \mathrm{s}$. The quantum confinement effect in silicon nanocrystals can be rejected as an explanation of this band. The low value of the decay time suggests that defects are implicated in the recombination process. A competition between two different processes, a nonradiative one related to defects and a radiative one related to transitions between the band tails states of spatially confined amorphous silicon clusters, cannot be rejected.

The room-temperature PL spectra in the range of 950-1650 nm are reported in Fig. 2 for the as-deposited SiO layer and for the annealed layers at different temperatures from 400 to $900{ }^{\circ} \mathrm{C}$. No PL is observed in this spectral range for the as-deposited sample. Two Er-related bands are well visible for the annealed samples. The bands at $980 \mathrm{~nm}$ and $1.54 \mu \mathrm{m}$ are characteristic of the radiative emission from the ${ }^{4} I_{11 / 2}{ }^{4} I_{15 / 2}$ and ${ }^{4} I_{13 / 2^{-}} I_{15 / 2}$ transitions of $\mathrm{Er}^{3+}$ ions, respectively. The intensity of the band at $980 \mathrm{~nm}$ is around two orders of magnitude lower than that of the $1.54 \mu \mathrm{m}$ band, as generally observed in similar systems. The intensity of the band at $1.54 \mu \mathrm{m}$ is an increasing function of the annealing 


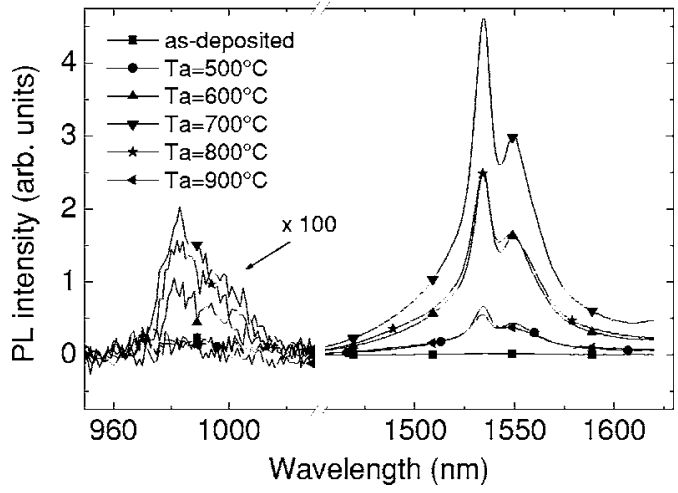

FIG. 2. Room temperature PL spectra in the range of 950-1600 nm for Er-doped $\mathrm{SiO}$ layers annealed at different temperatures Ta. The Er concentration is equal to 0.8 at. $\%$.

temperature until $700{ }^{\circ} \mathrm{C}$ where the intensity is maximal. Beyond this temperature, the PL intensity decreases with the annealing temperature. The intensity of the band located at $980 \mathrm{~nm}$ exactly follows the same annealing temperature dependence, which clearly demonstrates a strong correlation between these two bands.

\section{B. Decay time measurements}

Time-resolved-luminescence experiments were performed at room temperature at the wavelength corresponding to the Er-related PL peak maximum, i.e., at $1.535 \mu \mathrm{m}$. The time dependence of the sample annealed at $700{ }^{\circ} \mathrm{C}$ is reported in Fig. 3. As for all the samples, this time dependence can be well fitted by a single exponential decrease. For the sample annealed at $700{ }^{\circ} \mathrm{C}$, the decay time is equal to $1.5 \mathrm{~ms}$, which is very close to the decay time values generally obtained in Er-doped Si-nc. ${ }^{7,28,29}$ The decay time was measured for the different annealing temperatures and this dependence is represented in the inset of Fig. 3. For the sample annealed at $400{ }^{\circ} \mathrm{C}$, the decay time is equal to $0.67 \mathrm{~ms}$. This decay time is an increasing function of the annealing temperature until $600{ }^{\circ} \mathrm{C}$ where it is equal to $1.5 \mathrm{~ms}$. The decay time decreases for the higher annealing temperatures and reaches the value $1 \mathrm{~ms}$ for the sample annealed at $900{ }^{\circ} \mathrm{C}$. Few data are given in literature concerning the evolution of the decay time with the annealing tempera-

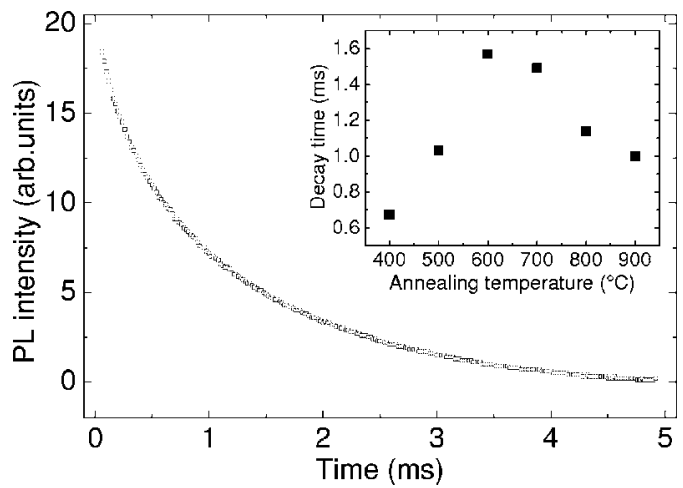

FIG. 3. Time dependence of the PL at $1.54 \mu \mathrm{m}$ for a sample annealed at $700{ }^{\circ} \mathrm{C}$ and with an Er concentration equal to 0.8 at. \%. The inset shows the evolution of the decay time with the annealing temperature.

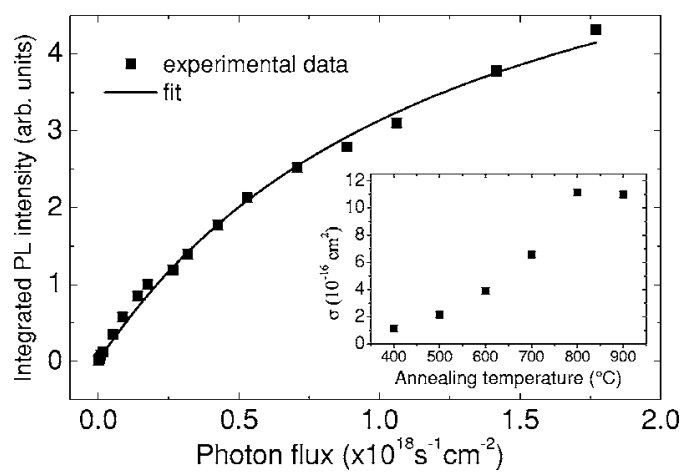

FIG. 4. Integrated PL intensity at $1.54 \mu \mathrm{m}$ as a function of the pumping photon flux for a sample annealed at $700{ }^{\circ} \mathrm{C}$ and for an Er concentration equal to 0.8 at. \%. The solid curve is a fit according to Eq. (1). The inset shows the annealing temperature dependence of the Er effective absorption cross section.

ture. In the work of Franzo et al., ${ }^{16}$ the Er decay time in Er-doped $\mathrm{Si}$-rich $\mathrm{SiO}_{2}$ films was measured for samples preannealed from 500 to $1250{ }^{\circ} \mathrm{C}$ to generate the appearance of pure silicon domains and annealed at $900{ }^{\circ} \mathrm{C}$ after Er implantation. In this case, the decay time is nearly independent of the preannealing temperature and is equal to around $2 \mathrm{~ms}$. In this present study, a clear evolution of the decay time is observed and suggests that nonradiative processes play an important role on the PL intensity.

\section{Pump power dependence}

The Er-related PL was measured as a function of the pump power. The evolution of the integrated PL band at $1.54 \mu \mathrm{m}$ with the photon flux is represented in Fig. 4 for the sample annealed at $700{ }^{\circ} \mathrm{C}$. For the low power values, the pump power dependence of the PL is linear and a saturation effect appears for the high power values. The model of energy transfer proposed by Franzo et al. ${ }^{16}$ that successfully describes the coupling between $\mathrm{Si}-\mathrm{nc}$ and $\mathrm{Er}^{3+}$ ions both embedded in a $\mathrm{SiO}_{2}$ matrix shows that the pump power dependence of the $1.54 \mu \mathrm{m}$ PL follows a hyperbolic law according to the following expression:

$$
I_{\mathrm{PL}} / I_{\max }=\sigma_{\mathrm{eff}} \phi \tau_{d}^{\mathrm{Er}} /\left(1+\sigma_{\mathrm{eff}} \phi \tau_{d}^{\mathrm{Er}}\right),
$$

where $\sigma_{\text {eff }}$ is an effective Er absorption cross section, $\tau_{d}^{\mathrm{Er}}$ is the decay time of the $1.54 \mu \mathrm{m} \mathrm{PL}$, and $\phi$ is the pumping laser photon flux. The effective cross section is defined by the following expression:

$$
\sigma_{\text {eff }}=\Lambda N \tau \sigma / \tau_{\text {tr }}^{\mathrm{Er}}
$$

where $N$ is the number of Si-nc, $\sigma$ is the exciton generation cross section, $\tau$ is the recombination time of the exciton, $\tau_{\mathrm{tr}}^{\mathrm{Er}}$ is the transfer time from the exciton to the $\mathrm{Er}^{3+}$ ion, and $\Lambda$ is an interaction volume which characterizes the interaction between the exciton and the $\mathrm{Er}^{3+}$ ion. In the present work, the same expression is applied where $N$ is the number of confined a-Si domains. Our experimental data are perfectly fitted by the expression (1), allowing us to obtain the effective cross section of Er. Taking into account an Er decay time equal to $1.5 \mathrm{~ms}$ for the sample annealed at $700{ }^{\circ} \mathrm{C}$, the value of $\sigma_{\text {eff }}$ is equal to $6.6 \times 10^{-16} \mathrm{~cm}^{2}$. This value is very close to 


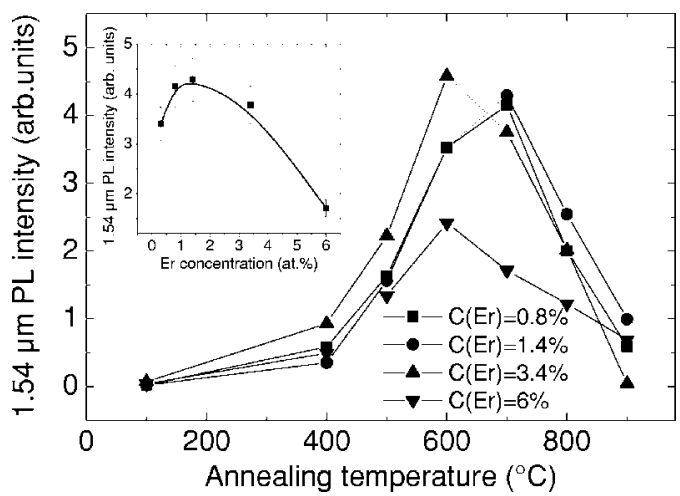

FIG. 5. Evolution of the $1.54 \mu \mathrm{m}$ PL intensity as a function of the annealing temperature for the different Er concentrations $C(\mathrm{Er})$. The inset shows the evolution of the $1.54 \mu \mathrm{m}$ PL intensity as a function of the Er concentration for samples annealed at $700{ }^{\circ} \mathrm{C}$. The solid curve is a guide for the eyes.

that obtained for Er-doped Si-nc $c^{10,30-32}$ and is around four orders of magnitude higher than the cross section corresponding to the direct absorption of Er embedded in an insulating matrix. ${ }^{33}$ The pump-power dependence of the Errelated PL was also measured for all the samples. It must be noticed that, for all the annealing temperatures, from 400 to $900{ }^{\circ} \mathrm{C}$, the expression (1) gives an excellent agreement with the experimental data. The evolution of the effective cross section of Er is represented as a function of the annealing temperature in the inset of Fig. 4. This value is an increasing function of the annealing temperature. The effective cross section of Er for the sample annealed at $900{ }^{\circ} \mathrm{C}$ is one order of magnitude higher than that of the sample annealed at $400{ }^{\circ} \mathrm{C}$.

\section{Influence of the Er concentration}

The Er-related PL was measured at room temperature as a function of the annealing temperature for different Er concentrations $C(\mathrm{Er})$ from $0.4 \%$ to $6 \%$. For all the concentrations, the evolution is similar with the existence of a PL maximum, as represented in Fig. 5. The maximum seems to depend slightly on the Er concentration. Indeed, for the high concentration values, this maximum happens at $600{ }^{\circ} \mathrm{C}$ while, for the low concentration values, this temperature is equal to $700{ }^{\circ} \mathrm{C}$.

It is also interesting to compare the Er-related PL intensity as a function of the Er concentration for the same annealing temperature. This dependence for the samples annealed at $700{ }^{\circ} \mathrm{C}$ is represented in the inset of Fig. 5. The highest PL intensity is obtained for an Er concentration equal to around 1\%. For higher Er concentration, the PL intensity decreases. The PL intensity of the sample with an Er concentration equal to $6 \%$ is around three times lower than that of the sample with an Er concentration equal to 0.8\%. This Er concentration dependence can be explained by a concentration quenching effect involved by nonradiative interactions between $\mathrm{Er}^{3+}$ ions, as already obtained in Er-doped $\mathrm{SiO}_{2}$ samples containing Si-nc ${ }^{34}$ and by the formation of optically inactive Er clusters.

The Er concentration PL dependence in the visible range was also studied and represented in Fig. 6. The PL intensity in the visible range is a decreasing function of the Er con-

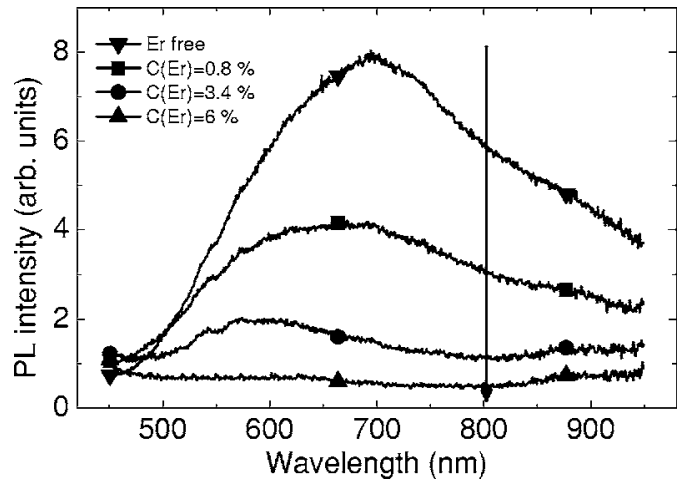

FIG. 6. Influence of the Er concentration on the PL band in the visible range for samples annealed at $700{ }^{\circ} \mathrm{C}$.

centration. By increasing this value by a factor of around 4 (from $0.8 \%$ to $3.4 \%$ ), the integrated visible PL band decreases by a factor of 3 . For a concentration equal to $6 \%$, this PL band disappears. Moreover, the decrease of the PL seems more pronounced around $800 \mathrm{~nm}$ where a hollow appears, as shown by the arrow. A similar decrease of the PL band located at around $700 \mathrm{~nm}$ was obtained in Er-doped amorphous $\mathrm{SiO}$ with the increase of Er concentration, which was interpreted by a coupling effect between a-Si clusters and the $\mathrm{Er}^{3+}$ ions. ${ }^{35}$

\section{DISCUSSION}

The evolution of the films structure with annealing treatments is important to understand the Er-related PL. Our previous results ${ }^{23,26}$ on undoped annealed $\mathrm{SiO}$ layers have clearly shown that the as-deposited samples are homogeneous $\mathrm{SiO}$ films which do not contain any detectable pure silicon phase. They also showed that pure amorphous silicon domains appear due to the phase separation of $\mathrm{SiO}$ into pure $\mathrm{Si}$ and pure $\mathrm{SiO}_{2}$. In these previous works, the presence of a silicon phase was mainly demonstrated by infrared absorption spectrometry and by Raman experiments. Indeed, it was demonstrated that the wave number of the $\mathrm{Si}-\mathrm{O}-\mathrm{Si}$ asymmetric stretching vibration is an increasing function of the annealing treatments, showing an evolution of the silicon oxide matrix from $\mathrm{SiO}_{1}$ to $\mathrm{SiO}_{2}$. As the chemical composition remained constant, this evolution is characteristic of the appearance of pure silicon in the layers. A direct signature of silicon was obtained by Raman spectroscopy which showed the characteristic transverse acoustical and transverse optical phonon modes of amorphous silicon. Due to their amorphous structure, silicon domains cannot be seen by conventional transmission electron microscopy. Moreover, other groups have recently demonstrated by energy filtered transmission electron microscopy experiments the existence of pure a-Si nanoparticles embedded in a silicon oxide matrix in annealed Si-rich $\mathrm{SiO}_{2}$ layers. ${ }^{16,35}$ Let us firstly discuss the existence of a possible coupling effect between a-Si domains and $\mathrm{Er}^{3+}$ ions. The results show that no Er-related PL is obtained in the as-deposited samples in which no pure silicon domain is present. After an annealing process, both the a-Si domains and the Er-related PL appear, suggesting that a-Si domains could play a crucial role on the Er luminescence. $\mathrm{Er}^{3+}$ ions 


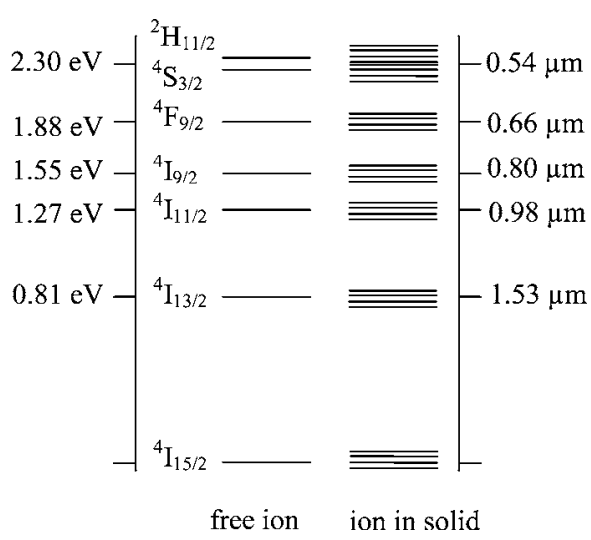

FIG. 7. Schematic energy level diagram of $\mathrm{Er}^{3+}$ for a free ion and for an ion in a solid. Both energies and corresponding wavelengths are given near the levels.

present different sublevels that could be responsible of the energy transfer from a-Si. The schematic energy-level diagram of $\mathrm{Er}^{3+}$ ions is represented in Fig. 7. Different resonant energy transfers could appear. The $\mathrm{SiO}$ defect band at $550 \mathrm{~nm}$ is resonant with the ${ }^{4} S_{3 / 2} \mathrm{Er}^{3+}$ electronic level. However, the coupling with this level is presumably very low because no Er-related PL is observed neither in the asdeposited sample nor in the sample annealed at $400{ }^{\circ} \mathrm{C}$, where the PL band at $550 \mathrm{~nm}$ is very high.

For higher annealing temperature, the PL band in the visible range is very large and covers the ${ }^{4} F_{9 / 2}$ and ${ }^{4} I_{9 / 2} \mathrm{Er}^{3+}$ electronic levels that are split due to the Stark effect. The energy of these levels corresponds to the wavelengths 660 and $800 \mathrm{~nm}$. The decrease of this band when the Er concentration increases suggests that the Er ions are coupled with the luminescent centers which give rise to this broad visible band. The possible correlation between this band and a-Si clusters, as discussed beyond, could be the signature of an energy transfer from a-Si to $\mathrm{Er}^{3+}$ by these two energy levels, in particular, with the ${ }^{4} I_{9 / 2}$ level, as shown by the preferential PL intensity decrease at around $800 \mathrm{~nm}$. Moreover, this level was mentioned to be implicated in the energy transfer from the exciton in Si-nc to the $\mathrm{Er}^{3+}$ ions in Er-doped layers containing Si-nc. ${ }^{8}$

In the case of Er-doped $\mathrm{Si}$-rich $\mathrm{SiO}_{2}$, an anneal at high temperature, greater than $1000{ }^{\circ} \mathrm{C}$, is generally necessary to obtain a high Er-related PL. This high annealing temperature is needed to generate the $\mathrm{Si}$-nc. In the case of Er-doped $\mathrm{SiO}$ layer, the best PL intensity at $1.54 \mu \mathrm{m}$ is obtained for an anneal around $700{ }^{\circ} \mathrm{C}$. The explanation why the maximum appears at this low temperature is not trivial because several parameters must be taken into account. First, it is generally recognized that the $\mathrm{Er}^{3+}$ ions must be optically activated by the presence of Er-O complexes that appear after annealing treatments. The increase of the Er-related PL can partially be explained by this complex formation. ${ }^{36}$ Moreover, we have shown that the effective Er cross section is an increasing function of the annealing temperature. This increase is probably due to the $\mathrm{SiO}$ phase separation that produces an increasing number of pure a-Si domains. Indeed, as shown in the model described above, the effective Er cross section is proportional to the number of silicon clusters. For an Er- doped sample with $C(\mathrm{Er})$ equal to $0.8 \%$, the increase of the $1.54 \mu \mathrm{m}$ PL intensity from an anneal at $400{ }^{\circ} \mathrm{C}$ to an anneal at $700{ }^{\circ} \mathrm{C}$ is equal to 6.8 while the effective cross section has been multiplied by a factor of 6 . The correlation between the effective cross section and the PL intensity at $1.54 \mu \mathrm{m}$ is very good up to the annealing temperature of $700{ }^{\circ} \mathrm{C}$, suggesting that the increase of the number of silicon domains is the main parameter that controls the Er-related PL intensity in this annealing-temperature range. Moreover, the measured decay time is an increasing function of the annealing temperature up to $700{ }^{\circ} \mathrm{C}$ which can be interpreted as a decrease of nonradiative recombination pathways. For higher annealing temperatures, the PL intensity decrease could be explained by several factors. A first explanation could be the phase separation process, which induces a coalescence phenomenon and then would lead to a decrease of the silicon clusters number. However, the coalescence phenomenon probably appears for annealing temperatures greater than $950{ }^{\circ} \mathrm{C}$, as shown in Ref. 27. Moreover, the effective cross section, which is proportional to the number of domains, does not decrease for the high annealing temperatures. The decay time of the Er-related PL at $1.54 \mu \mathrm{m}$ is a decreasing function of the annealing temperature for temperatures greater than $700{ }^{\circ} \mathrm{C}$, which suggests that a nonradiative deexcitation process appears. This process is not clearly identified but could be due to the Er-Er interaction involved by a possible diffusion of Er in the layer, as already shown in Er-doped silica films. ${ }^{37}$ This explanation could also allow us to understand why the optimal annealing temperature is lower for the high Er concentration values. Indeed, for high Er concentration, the diffusion and segregation of Er should appear for lower temperature and then lead to the decrease of the PL intensity at lower annealing temperatures.

\section{CONCLUSION}

Er-doped amorphous $\mathrm{SiO}$ thin films were prepared by the coevaporation method. The influence of the annealing temperature and of the Er concentration on the PL properties was studied. Two sharp PL bands at 0.98 and $1.54 \mu \mathrm{m}$ were assigned to the $\mathrm{Er}^{3+}$ ions. The high Er-related PL was interpreted by an indirect excitation process of Er from the a-Si clusters which could act as sensitizers. It is also shown that the optimal annealing temperature is equal to around $700{ }^{\circ} \mathrm{C}$, which is far below the annealing temperature required for Er-doped samples containing Si-nc. The increase of the Errelated PL with annealing temperature up to $700{ }^{\circ} \mathrm{C}$ is assigned to an increase of the a-Si clusters number and by a decrease of nonradiative centers. Beyond $700{ }^{\circ} \mathrm{C}$, the PL intensity decrease is attributed to the appearance of nonradiative processes such as interaction between Er atoms. The PL decay time at $1.54 \mu \mathrm{m}$ and the effective Er absorption cross section are typically equal to $1.5 \mathrm{~ms}$ and $10^{-16} \mathrm{~cm}^{2}$, respectively. These values are very close to those obtained in Erdoped samples containing Si-nc.

${ }^{1}$ A. Polman, J. Appl. Phys. 82, 1 (1997).

${ }^{2}$ F. Priolo, G. Franzo, S. Coffa, and A. Carnera, Phys. Rev. B 57, 4443 (1998).

${ }^{3}$ G. Franzo, F. Priolo, S. Coffa, A. Polman, and A. Carnera, Appl. Phys. 
Lett. 64, 2235 (1994).

${ }^{4}$ F. Priolo, G. Franzo, S. Coffa, A. Polman, S. Libertino, R. Barklie, and D. Carey, J. Appl. Phys. 78, 3874 (1995).

${ }^{5}$ S. Coffa, G. Franzo, F. Priolo, A. Polman, and R. Serna, Phys. Rev. B 49, 16313 (1994)

${ }^{6}$ G. N. van den Hoven, J. H. Shin, A. Polman, S. Lombardo, and S. U. Campisano, J. Appl. Phys. 78, 2642 (1995).

${ }^{7}$ P. G. Kik, M. L. Brongersma, and A. Polman, Appl. Phys. Lett. 76, 2325 (2000).

${ }^{8}$ G. Franzo, D. Pacifici, V. Vinciguerra, F. Priolo, and F. Iacona, Appl. Phys Lett. 76, 2167 (2000).

${ }^{9}$ M. Fujii, M. Yoshida, Y. Kansawa, S. Hayaski, and K. Yamamoto, Appl. Phys. Lett. 71, 1198 (1997).

${ }^{10}$ G. Franzo, V. Vinciguerra, and F. Priolo, Appl. Phys. A: Mater. Sci. Process. 69, 3 (1999).

${ }^{11}$ A. J. Kenyon, C. E. Chryssou, C. W. Pitt, T. Shimizu-Iwayama, D. E. Hole, N. Sharma, and C. J. Humphreys, J. Appl. Phys. 91, 367 (2002).

${ }^{12}$ G. Wora Adeola, O. Jambois, P. Miska, H. Rinnert, and M. Vergnat, Appl. Phys. Lett. 89, 101920 (2006).

${ }^{13}$ J. H. Shin, M. Kim, S. Seo, and C. Lee, Appl. Phys. Lett. 72, 1092 (1998).

${ }^{14}$ M. Fujii, M. Yoshida, S. Yahashi, and K. Yamamoto, J. Appl. Phys. 84, 4525 (1998).

${ }^{15}$ C. E. Chryssou, A. J. Kenyon, T. S. Iwayama, C. W. Pitt, and D. E. Hole, Appl. Phys. Lett. 75, 2011 (1999).

${ }^{16}$ G. Franzo, S. Boninelli, D. Pacifici, F. Priolo, F. Iacona, and C. Bongiorno, Appl. Phys. Lett. 82, 3871 (2003).

${ }^{17}$ A. Meldrum, A. Hryciw, A. N. MacDonald, C. Blois, T. Clement, R. De Corby, J. Wang, and Q. Li, J. Lumin. 121, 199 (2006).

${ }^{18}$ T. Oesterreich, G. Swiatkowski, and I. Broser, Appl. Phys. Lett. 56, 446 (1990).

${ }^{19}$ M. S. Bresler et al., Appl. Phys. Lett. 67, 3599 (1995).

${ }^{20}$ I. N. Yassievich, M. Bresler, O. B. Gusev, J. Non-Cryst. Solids 226, 192
(1998).

${ }^{21}$ A. R. Zanatta, L. A. O. Nunes, and L. R. Tessler, Appl. Phys. Lett. 70, 511 (1996).

${ }^{22}$ V. F. Masterov, F. S. Nasredinov, P. P. Seregin, V. Kh. Kudoyarova, A. N. Kuznetsov, and E. I. Terukov, Appl. Phys. Lett. 72, 728 (1998).

${ }^{23}$ H. Rinnert, M. Vergnat, G. Marchal, and A. Burneau, Appl. Phys. Lett. 72, 3157 (1998).

${ }^{24}$ A. J. Kenyon, P. F. Trwoga, C. W. Pitt, and G. Rehm, J. Appl. Phys. 79, 9291 (1996)

${ }^{25}$ K. S. Min, K. V. Shcheglov, C. M. Yang, H. A. Atwater, M. L. Brongersma, and A. Polman, Appl. Phys. Lett. 69, 2033 (1996).

${ }^{26}$ H. Rinnert, M. Vergnat, and A. Burneau, J. Appl. Phys. 89, 237 (2001).

${ }^{27}$ O. Jambois, H. Rinnert, X. Devaux, and M. Vergnat, J. Appl. Phys. 100, 123504 (2006)

${ }^{28}$ F. Gourbilleau, R. Madelon, C. Dufour, and R. Rizk, Opt. Mater. (Amsterdam, Neth.) 27, 868 (2005).

${ }^{29}$ D. Pacifici, G. Franzo, F. Priolo, F. Iacona, and L. Dal Negro, Phys. Rev. B 67, 245301 (2003).

${ }^{30}$ A. J. Kenyon, C. E. Chryssou, C. W. Pitt, T. Shimizu-Iwayama, D. E. Hole, N. Sharma, and C. J. Humphreys, J. Appl. Phys. 91, 367 (2002).

${ }^{31}$ C. C. Kao et al., J. Appl. Phys. 98, 013544 (2005).

${ }^{32}$ F. Gourbilleau, M. Levalois, C. Dufour, J. Vicen, and R. Rizk, J. Appl. Phys. 95, 3717 (2004).

${ }^{33}$ F. Priolo, G. Franzo, D. Pacifici, V. Vinciguerra, F. Iacona, and A. Irrera, J. Appl. Phys. 89, 264 (2001).

${ }^{34}$ P. G. Kik and A. Polman, J. Appl. Phys. 88, 1992 (2000).

${ }^{35}$ A. Hryciw, C. Blois, A. Meldrum, T. Clement, R. De Corby, and Q. Li, Opt. Mater. (Amsterdam, Neth.) 28, 873 (2006)

${ }^{36}$ F. Priolo, S. Coffa, G. Franzo, C. Spinella, A. Carnera, and V. Bellani, J. Appl. Phys. 74, 4936 (1993).

${ }^{37}$ A. Polman, D. C. Jacobson, D. J. Eaglesham, R. C. Kistler, and J. M. Poate, J. Appl. Phys. 70, 3778 (1991). 